\title{
Substance precedes methodology: on cost-benefit analysis and equity
}

\author{
Karel Martens
}

Published online: 17 September 2011

(C) The Author(s) 2011. This article is published with open access at Springerlink.com

\begin{abstract}
While distributive aspects have been a topic of discussion in relation to costbenefit analysis (CBA), little systematic thought has been given in the CBA literature to the focus of such an equity analysis in evaluating transport projects. The goal of the paper is to provide an overview of the various directions an equity analysis, carried out within the context of a social cost-benefit analysis, could take. The paper starts from the widely-shared definition of distributive justice: the morally proper distribution of goods and bads over members of society. Following this definition, carrying out an equity analysis requires that decisions are made about: (1) the benefits and costs that are distributed through a transport project; (2) the members of society between whom benefits and costs are distributed; and (3) the distributive principle that determines whether a particular distribution is fair. Much of the discussions about cost-benefit analysis and equity do not address these questions in any systematic way. The paper aims to provide a framework. Three sets of benefits and costs are identified as a possible focus of an equity analysis: (1) net benefits; (2) mobility-enhancing benefits; and (3) individual benefits and costs. For each set, a discussion follows regarding the way in which members of societies could be divided into meaningful groups, as well as the possible yardstick for judging whether a certain distribution is fair. While the paper acknowledges that the choice between the three sets is ultimately a political decision, it ends with a set of arguments that suggest that the equity analysis of transport projects should focus first and foremost on the mobility-enhancing benefits generated by such projects.
\end{abstract}

Keywords Cost-benefit analysis $\cdot$ Justice $\cdot$ Equity $\cdot$ Net benefits $\cdot$ Mobility

\section{Introduction}

Cost-benefit analysis (CBA) is widely used in transportation planning as a method for ex ante evaluation of the benefits and costs of proposed transport projects (see e.g. the special

\footnotetext{
K. Martens $(\bowtie)$

Institute for Management Research, Radboud University Nijmegen, P.O. Box 9108, 6500 HK Nijmegen, The Netherlands

e-mail: k.martens@fm.ru.nl

URL: www.ru.nl/gap/koppeling/planologie/martens/
} 
issue of Transport Policy 2000). It generates data on the economic efficiency of a transport project, which can be defined as the maximization of the net contribution of the project to the national income (Hill 1973; Campbell and Brown 2003). By its nature, cost-benefit analysis aggregates the costs and benefits generated by a transport project into net benefits (or net losses). It does not provide insight into the way in which these benefits and costs are distributed over different population groups. Yet, decision-makers and the general public alike are not only interested in the economic efficiency of a project, but also in its equity: in the extent to which a project is characterized by a fair distribution of benefits and costs over various population groups (see e.g. Schofield 1987).

Given the dominance of cost-benefit analysis in the appraisal of transport projects throughout much of the world, it may therefore come as no surprise that the distributive question is a key issue in the discussions about the form and shape of cost-benefit analysis (Brent 1996). What is remarkable, though, is the fact that most of these discussions focus on the methodology to integrate distributive considerations into the existing CBA framework. This line of reasoning has resulted, among others, in the development of the methodology of distributive weights, in which benefits accrued by different income groups are ascribed different weights (see e.g. Mishan 1976; Campbell and Brown 2003). Another example is the common practice to base the value of travel time savings on equity values rather than market-based values, in an effort to level-out the impact of income differences (e.g., Gunn 2000; Jara-Diaz 2000; Mackie et al. 2001).

The emphasis on methodology stands in sharp contrast to the limited attention in the CBA literature for the substance of the proposed equity analysis. Researchers hardly ever systematically deal with the question which distributive concerns should be addressed within the CBA context (but see Schade et al. 2004). Are we concerned that the rich accrue more net benefits from a transport project than the poor? Or are we concerned about the (lack of) mobility of women in comparison to men? Or about an unfair increase in air pollution in deprived neighborhoods? Without an explicit definition of what we are interested in, no proper equity analysis can be carried out. Before engaging into methodological questions, it is therefore of key importance to specify the substance of the equity analysis.

The aim of this paper is to explore possible alternative specifications of the substance of an equity analysis, in an effort to provide a solid base for a more fruitful discussion about the distributive question within the CBA context. The exploration takes as its starting point the current dominance of cost-benefit analysis as an evaluation tool in everyday practice of transportation planning (e.g., Bristow and Nellthorp 2000). While some argue, based on theoretical arguments, that cost-benefit analysis should be done away with altogether (e.g., Kelman 2002), the paper starts from the de facto dominance of cost-benefit analysis. This suggests that any equity analysis of proposed transport projects should be closely linked to cost-benefit analysis, if it is to gain relevance for practice. This link could take the shape of a direct integration of efficiency and equity concerns within the existing CBA methodology, even though it has been argued that such an integration is at odds with the theory underlying cost-benefit analysis (see Johansson-Stenman 2005). The link could also be of more limited in character, in which case the equity analysis might be linked to the CBA framework in terms of the data used, the type of evaluation indicators generated, and/ or the stage in the decision-making process in which the equity analysis is carried out and the results are presented to decision-makers and/or the wider public. The phrase 'within the CBA context' used throughout the paper refers to the latter meaning.

The exploration of the possible substance of an equity analysis will start from the widely used definition of equity_also referred to as fairness or justice-as the morally 
proper distribution of goods and bads over members of society (e.g., Boucher and Kelly 1998; Miller 1999). From the perspective of equity, human society is perceived first and foremost as a distributive community in which people produce things that are shared, divided and exchanged in specific ways. The way these 'things' - commonly defined as goods and bads or benefits and costs - are and should be distributed is the subject of study. While the distributive approach is certainly not the only possible conceptualization of justice (e.g., Young 1990), it is widely considered a key component of any notion of justice.

The distributive approach to equity thus suggests that three questions need to be answered to determine the substance of an equity analysis: (1) Which goods and bads or benefits and costs should be at the focus of the equity analysis?; (2) How should 'members of society' be conceptualized, i.e. which population groups should be distinguished?; and (3) What constitutes a 'morally proper distribution', i.e. which yardstick or distributive principle should be used to determine whether a particular distribution is fair? In order to determine the substance of any equity analysis, explicit attention will have to be paid to each of these elements and to their interrelationships. The argument has to start from an explicit and well-motivated decision regarding the benefits and/or costs that should be addressed in the equity analysis. Based on this, members of society can be divided into meaningful groups. Finally, it is necessary to determine which distributive principle to use as a yardstick to judge the distribution of the selected benefits and/or costs.

The paper starts with a discussion of three alternative conceptualizations of the benefits and costs generated by a transport project ("Net benefits", "Mobility-enhancing benefits", and "Single benefits and costs" sections). Based on these conceptualizations, also the way in which members of society should be divided into groups is addressed. Where relevant, these three sections build on the substantial body of literature addressing transport and equity (see for a review Schweitzer and Valenzuela 2004; Schweitzer and Stephenson 2007). Then, in "Possible distributive principles" section, three different distributive principles are discussed, each of which could be used as a yardstick for assessing the fairness of a distribution of a particular benefit or cost. The "Consequences for methodology" section explores the link between substance and methodology, and shows, through examples, the limitations of existing methodologies to address each of the equity concerns distinguished in this paper. The paper ends with a brief discussion of the implications of the findings for the practice of cost-benefit analysis. It will be concluded that the discussion about the adequate methodology to address equity concerns within cost-benefit analysis has to be preceded by a debate about the equity concerns that should be at the heart of the analysis. Furthermore, the example presented at the end of the paper stresses, in line with much of the existing literature (e.g., Beatley 1988; Levinson 2002), that an adequate evaluation of the distributional impacts of transport projects requires an assessment alongside but separate from cost-benefit analysis. This observation holds irrespective of the chosen substance of the equity analysis.

\section{Net benefits}

The first benefit that could be at the center of the equity analysis is the net benefit generated by a transport project. The argument to focus on the distribution of this benefit follows the lines of standard cost-benefit analysis and its emphasis on total costs and benefits generated by a project. This emphasis is based on two assumptions underlying standard costbenefit analysis: (1) each of the positive or negative impacts generated by a project can be translated into monetary terms and can thus be related to as a benefit or a cost; and (2) these 
benefits and costs are substitutes of one another in monetary terms (Sen 2001; Needham 2006). Following these assumptions, standard cost-benefit analysis is not about the individual benefits and costs generated by a (transport) project. The assessment of the size of the individual benefits and costs is merely seen as a necessary step in the calculation of total net benefits and, ultimately, in the assessment of the economic efficiency of a project. From the standard CBA perspective it is not important whether a project generates positive net benefits due to substantial travel time savings or because of large reductions in road fatalities. The size of the monetary values is what counts.

If these two assumptions are accepted, it follows that money is not only the single currency' in which all costs and benefits are expressed, but that it is the only benefit whose distribution may warrant explicit analysis. In other words, following this line of reasoning, the equity analysis has only to address the way in which the total monetary value of a project- the net benefits-is distributed over various population groups.

The focus on net benefits in the equity analysis does not imply any particular division of the population into groups. The division will depend, by and large, on political considerations. Depending on the project and the circumstances, decision-makers may want to differentiate between groups in terms of income, gender, age, ethnic background, jurisdiction or other criteria. Note that the concern for the distribution of net benefits implies that the equity analysis does not provide insight into the distribution of benefits that may be of particular value for certain groups. For instance, while the equity analysis can shed light on the distribution of net benefits over e.g. income groups, it would not provide insight whether low income groups reap net benefits because of a reduction in motorization costs - and hence may experience a real improvement in disposable income-or due to a reduction in air pollution.

\section{Mobility-enhancing benefits}

The second answer to the question which benefits(s) and/or costs should take center stage in the equity analysis starts from the goals of the project assessed in cost-benefit analysis. The goal of any investment project is first and foremost to improve a specific area of life. It does so by providing specific goods to people. In case of transport projects, the prime goal of most investments is to improve the ability of people to travel from one place to another. ${ }^{1}$ The projects achieve this goal by providing new transport infrastructure and/or services (e.g., a road, railway line, bus lane, station). Put in general terms, an investment project is first of all a tool to assist people in-kind, that is, a tool to provide people with specific goods, services or infrastructure, rather than a tool to generate cash income or net benefits for those people or the society at large (Brent 1996).

The distinction between net benefits and in-kind assistance is especially relevant in case a good provided by an investment project cannot be acquired in any other way (e.g., through the market). In case of transport projects this is mostly the case: virtually all infrastructure facilities (roads, bus lanes, railway lines, stations, bicycle paths) are collectively provided and cannot be purchased through the market place or in any other way. Moreover, no alternative 'products' are available that could replace (most of) the services provided through transport infrastructure. If this is the case, the key question from an equity perspective is how the goods that are only or primarily provided through a transport

\footnotetext{
${ }^{1}$ An exception to this are transport projects that focus on the increase of traffic safety, although it can be argued that these, too, improve the potential mobility of people in some way.
} 
project are distributed over various population groups. The distribution of these core benefits should be the object of analysis rather than the distribution of total net benefits. Linked to the goal of a transport project, these core benefits encompass all benefits that improve the ability of people to travel from one place to another, in other words, the benefits that enhance the potential mobility of people: the capacity to overcome distance in physical space (Sager 2005). Potential mobility is here defined as a person's ability to travel through space, given a particular (residential) location, and time and money budget. Unlike most accessibility measures, it does not (necessarily) encompass destinations or land use patterns (Geurs and van Wee 2004).

The identification of potential mobility as the most important benefit distributed through transport projects implies that the equity analysis should focus on all those benefits included in cost-benefit analysis that improve the ability of people to travel from one place to another. Two of the benefits can be considered to belong to this group of core benefits: travel time savings and vehicle operation costs. Both of them make it easier to travel, either in terms of time or in terms of money. Population groups that receive large shares of these benefits will experience an improvement in their potential mobility, while those groups that do not receive any of these benefits will not see any improvement. The concept of potential mobility can thus be operationalized with relative ease within the CBA context.

The focus on mobility-enhancing benefits implies that the division of the population into groups should be based on the way in which potential mobility is divided over members of society. While data on actual mobility of population groups is often most readily available, it may be clear that actual mobility is a poor indicator of a person's potential mobility. Actual travel patterns are to a large extent a reflection of phase in life and behavioral patterns, which differ widely between people and population groups. For instance, elderly people tend to travel substantially less than people who participate in the workforce, or than people who combine work and household tasks. However, this does not necessarily mean that their potential mobility is lower than either of these groups.

In a theoretical sense, potential mobility is a result of system characteristics (available infrastructure, timetables, etc.) and personal characteristics (location of residence, vehicle availability, possession of transit pass, etc.). A wide body of literature exists in which these characteristics have been combined into measures to assess potential mobility or access (see e.g. Handy and Niemeier 1997; Geurs and van Wee 2004; Dong et al. 2006). However, within the context of cost-benefit analysis it is practically infeasible to divide population groups based on the characteristics employed in these types of measures, because the necessary data are rarely collected within the CBA context. Given this practical limitation, a proxy of potential mobility will have to be used to divide the population into relevant groups. The most suitable proxy, which can be easily applied within the CBA context, is a combination of car ownership and income. The literature on transport and equity emphasizes the strong interrelationship between both characteristics and potential mobility (e.g., Ihlanfeldt 1993; Blumenberg 2004; Stoll 2005). Especially car ownership has been shown to be closely related to access to opportunities (e.g., Kwan 1999; Lucas 2004; Benenson et al. 2010), even though the impact of car ownership on potential mobility may be limited in some locations, such as dense downtown areas (e.g., Kwok and Yeh 2004). Given this situation, car availability could be used as the prime criterion to divide the population into groups with high and lower levels of potential mobility. Furthermore, since potential mobility is also related to transport costs, an additional partitioning into income groups may supplement the initial division by car ownership level (e.g., Cain and Jones 2007). 


\section{Single benefits and costs}

The third answer to the question which benefits and costs should take center stage in the equity analysis follows the lines of the ethical critique on cost-benefit analysis. Much of this critique underscores that the benefits and costs generated by a transport project - or any other type of investment project—are not simply interchangeable (Frank 2001; Holland 1996). Critics that follow this ethical line of reasoning argue that it does make a difference if a population group experiences a raise in taxes or an increased level in air pollution as a result of a new transport project. While both of them can perhaps be viewed as a cost, the translation of air pollution levels into monetary terms is inherently problematic from an ethical point of view (see Adler and Posner 2001; Kelman 2002). From an ethical point of view, so the argument goes, increased air pollution can simply not be equated with an increased contribution to construction costs through taxation, as the impacts on human life are fundamentally different and therefore require different treatment. Following this line of analysis, it could be argued, in line with much of the literature (e.g., Sayers et al. 2003; Geurs et al. 2009) that the equity analysis should encompass a complete overview of the distribution of all the costs and benefits generated by a transport project. In this way, each of the costs and benefits and their diverse impacts on human life can be given its due.

Furthermore, as the ethical critique to cost-benefit analysis suggests that a translation of benefits/costs into monetary terms is inherently problematic, it follows that the equity analysis should not focus on these monetary values, but rather on the absolute values of each benefit/cost under discussion. In case of air pollution, for instance, the question should be to what extent a project increases or reduces the level of polluting substances in the air, such as $\mathrm{NO}_{x}$ or particles, or on the expected health impacts of changes in air pollution levels. Similarly, in case of noise, an increase or decrease in $\mathrm{dB}(\mathrm{A})$ or in noise-related health problems, is what counts. It may be clear that the focus on the absolute values shapes the possible format of an equity analysis. Not only should each benefit and cost be addressed separately, but separate measures and indicators will also have to be used.

The focus on individual costs and benefits has implications for the division of the population into groups. The difference in character between the different costs and benefits generated by a transport project suggests that various divisions may be called for. For instance, in case of air pollution, a distinction according to sensitivity to air pollution may be most relevant. In practice, this may imply a division into age groups, given the high sensitivity to air pollution among especially young children and older population groups (e.g., Bae et al. 2007). The same distinction could be used for accident risks, although a distinction by transport mode may also be relevant here, given the differences between car passengers, pedestrians, and cyclists in terms of their vulnerability and accident risk per passenger kilometer (Pucher and Dijkstra 2000). In contrast, following the argumentation in the previous section, the analysis of travel time savings could distinguish between carowning and car-less households. And when focusing on construction and maintenance costs, it seems reasonable to divide the population into income groups. Other examples could be provided. What the examples show is that, from the perspective used here, each cost or benefit generated by a transport project will require a different division of the population.

Note that this 'disaggregated' approach to the evaluation of the distribution of costs and benefits generated by a transport project has been propagated by Lichfield as early the 1960s and 1970s (e.g., Lichfield 1966). It is also in line with much of the literature on transport and environmental justice (e.g., Mills and Neuhauser 2000; Morello-Frosch et al. 2001; Brainard et al. 2002), as well as with the practice of environmental impact 
statements (e.g., Fischer 2002). Also, some countries have adopted this approach in recent years, often in parallel to regular cost-benefit analysis, such as the UK Department of Transport (see www.webtag.org.uk).

Table 1 provides an overview of the possible foci of an equity analysis for transport investment projects. It links the object of equity analysis - the costs/benefits whose distribution is object of analysis - with the most relevant division of the referent population into groups. Note that a further specification of population groups in terms of spatial scale is often called for, as benefits are likely to be distributed unevenly over space and hence within population groups (see below) (e.g., Williams 1999). In order to translate the foci of analysis into equity concerns and a framework for an equity analysis, it is necessary to link them to notions of a fair distribution. This is the subject of the next section.

\section{Possible distributive principles}

In "Introduction" section, three questions have been distinguished that need to be addressed before engaging in an equity assessment. The previous sections provided three possible answers to the first two questions. This section focuses on the third question: Which distributive principle should be used as the yardstick to assess the distribution of costs and benefits through a transport project?

The discussion below starts from the observation, dating back at least to Aristotle, that equality can be perceived as the 'default' option for the distribution of benefits and costs over members of society (Kolm 1996). That is to say, an equal division of benefits or costs over different population groups is considered as fair or just, unless convincing arguments can be provided for an alternative distribution (Smith 1994). Lacking such arguments, equality remains as the correct way to distribute a good. Following this argument, I will discuss three distributive principles that can be considered as variations on the principle of equality. As will be shown below, these principles may indeed cover much of the concerns of decision-makers and the wider public regarding the distribution of the three types of benefits/costs distinguished above. At the same time, it should be pointed out that other distributive principles are distinguished in the social justice literature, which might be applicable to the distribution of the benefits/cost generated by a transport project, such as need (e.g., Marx discussed in Walzer 1983), individual desert, i.e. rewards for past contributions, burdens or sacrifices (e.g., Sadurski 1985), or entitlement (e.g., Nozick 1974). However, it is beyond the scope of this paper to explore the applicability of each of these distributive principles (see Beatley 1988 for an exploration regarding infrastructure planning).

The first principle to be discussed here is the principle of 'simple equality' or 'pure equality'. This principle refers to a distribution in which each person or population group receives the same share of a certain benefit or cost, irrespective of the characteristics of the person or the group. In other words, when the principle of equality is applied, it makes no

Table 1 Possible foci of an equity analysis of transport investment projects

\begin{tabular}{ll}
\hline Object of equity analysis & Division of population groups \\
\hline Net benefits & By income or other division \\
Mobility-enhancing benefits & By car ownership and income \\
Single benefits and costs & By criteria relevant for each \\
& benefit/cost \\
\hline
\end{tabular}


difference whether a group is vulnerable to a specific cost (e.g., air pollution), whether the group has special needs, or whether the group already enjoys a large share of the benefit or cost under consideration. For this reason, the principle of equality is sometimes referred to in the literature as 'pure equality' or 'simple equality' (Walzer 1983). When applied to each of the three types of costs/benefits discussed above, the criterion of equality implies that a proposed transport project is fair if either the net benefits, the mobility-enhancing benefits, or the single benefits and costs, as generated by that project, are distributed in an equal way over the population groups distinguished in each case.

The second distributive principle to assess the equity impacts of transport investment projects is the avoidance of disproportionate distributions, which has been used in a number of environmental justice studies (see e.g. Forkenbrock and Schweitzer 1999) and has been put forward by scholars of cost-benefit analysis (e.g., Schofield 1987). The principle is based on the understanding that achieving pure equality in the distribution of benefits/costs generated by a transport project is virtually impossible in actual practice. This is, on the one hand, related to the fact that costs and benefits generated by a transport project are inevitably unequally distributed over space. On the other hand, studies have shown that the distribution of costs/benefits over population groups depends to a substantial extent on the scale of analysis (Williams 1999). Taken together, these observations provide a strong argument against a straightforward application of the criterion of pure equality to transport projects. However, given the moral appeal of the criterion of equality, it may be expected that both decision-makers and the wider public may be committed to some level of equality. Given this commitment and the virtual impossibility to achieve perfect equality, differences in benefits reaped by, or costs borne by, population groups may be considered acceptable, as long as these differences are not disproportional, i.e. as long as the deviation from the ideal of pure equality is considered to be within reasonable boundaries. From this analysis follows that a second distributive principle that can be used as a yardstick to assess the equity impacts of transport projects is the avoidance of disproportionate distributions.

The third distributive principle that can be used as a yardstick to assess the equity impacts of a transport project is equalization (Smith 1994). The distributive criterion of equalization is also a principle of equality, but with a different 'benchmark' than the criterion of 'pure' or 'simple' equality. The goal as defined by the criterion of equalization is a society in which the benefits/costs under consideration, e.g. income, travel times, or air pollution, are distributed in an equal way. The criterion thus links the distribution of costs/ benefits as generated by a project, to the overall distribution of those costs/benefits in society. Project alternatives that distribute costs or benefits in such a way that they narrow the existing gaps in society are preferred over alternatives that consolidate or widen these gaps (see also Rietveld et al. 2007, p. 33). The equalization criterion is sometimes referred to as the "compensatory principle" and can be interpreted as a version of the principle of a 'good redistribution of wealth' put forward as early as 1951 by Little (discussed in Schofield 1987, pp. 23-24) in his discussion of cost-benefit analysis.

Each of the three principles can be applied to the foci of the equity analysis discussed in the previous sections. For instance, the principle of equality may be applied to the distribution of net benefits over income groups. In that case, a transport project will receive a more positive evaluation, the more the distribution of net benefits over all income groups comes closer to the ideal of pure equality. Projects that clearly generate more net benefits for one income group than another receive a negative evaluation, irrespective whether rich or poor population groups reap a disproportionally large share of total net benefits. Likewise, the criterion of avoidance of disproportionate distributions could be applied to 
the distribution of mobility-enhancing benefits. In that case, transport projects are evaluated positively as long as neither car-owning nor car-less households receive a disproportionally large share of travel time savings, i.e. as long as the deviation from a perfectly equal distribution remains within a predefined range. Note that, in actual practice, this may be achieved by combining a road and a transit project into one investment program. A final example concerns the application of the principle of equalization to single benefits. In case this criterion is applied to e.g. road safety levels, a transport project receives a better score the more it contributes to leveling out the existing differences in road safety between neighborhoods.

Obviously, the choice for each of the principles reflects different opinions about what is a fair or just distribution of the benefit/cost under consideration. For instance, the decision to use the principle of equality in the assessment of transport projects implies that decisionmakers-or the wider public - are of the opinion that the status quo represents a fair situation. The application of this principle implies that a project alternative that maintains the status quo will be preferred over an alternative that would imply a (substantial) change in the existing distribution of the benefit/cost under consideration. In contrast, the use of the principle of equalization implies that decision-makers are interested in narrowing existing gaps in society, and that they consider transport projects as a proper means to achieve at least some of the desired redistribution. This can be gaps in income levels (which would result in a focus on net benefits or, perhaps, vehicle operation costs), in potential mobility (resulting in a focus on travel time savings, vehicle operation costs, and perhaps accident risks), or in the level of pollution experienced by various population groups. Furthermore, it needs to be noted that decision-makers may have other distributive concerns than those discussed here and may therefore prefer to apply another yardstick to assess the fairness of proposed transport projects, as highlighted above (see Beatley 1988; also Geurs et al. 2009). Finally, decision-makers may be guided by particular equity concerns, but may be of the opinion that other means than large-scale transport projects are best used to guarantee the desired (re)distribution of a certain cost or benefit over population groups (see Campbell and Brown 2003, p. 245). For instance, if decision-makers are concerned about the potential mobility of the poor or the handicapped, dedicated policies could be developed and measures taken to address this issue (e.g., taxi vouchers or increased transit subsidies). Also, in such a case, decision-makers can consider reverting to the use of compensation measures to correct for the undesirable distributive outcomes of a preferred transport investment project, such as tax measures if the equity concern relates to the distribution of net benefits.

\section{Consequences for methodology}

The substance of the equity analysis has important consequences for the methodology with which to address distributive issues within the CBA context. Starting from the substance of the analysis, it becomes clear that the two methodologies most widely discussed in the literature on transport project appraisal-distributional weights and equity values of time-actually focus on two different equity concerns. The methodology of distributional weights addresses the concern that transport projects will widen the gaps in overall welfare between different income groups; hence a focus on the distribution of net benefits generated by a transport project and on the criterion of equalization. Equity values for travel time savings, on the other hand, are not applied in cost-benefit analysis because of a concern over income gaps, but because of a concern over the way in which travel time 
savings will be distributed over different population groups. In case market-based values of travel time savings are used, transport projects that reduce travel times for groups with high values of time (often, but not only, high income groups) will score consistently better in project appraisal than comparable projects that mainly generate travel time savings for groups with low values of time (often, but not only, poor population groups). The use of equity values eliminates at least some of this bias (but see Martens 2006). The underlying equity concern thus has to do with the way in which mobility-enhancing benefits are distributed over different (income) groups, rather than with the distribution of net benefits over these groups. While these travel time savings are ultimately translated into monetary values in a cost-benefit analysis, the primary motivation for applying equity values lies in the concern about the distribution of travel time savings, and not overall benefits, over population groups.

A further analysis shows that a focus on the substance of the equity analysis also illuminates the limitations of the existing methodologies to address different concerns about the way a given benefit or cost is distributed over groups in society (i.e. distribution in relation to the distributive principles discussed above). In order to illustrate this point, the example of distributional weights will be discussed. While distributional weights have hardly been used in actual practice (e.g., Geurs et al. 2009; Mackie et al. 2001) and alternative approaches have been developed in recent years to assess efficiency and equity simultaneously (e.g., Rietveld et al. 2007), textbooks tend to focus on distributional weights as a suitable methodology to address equity concerns in cost-benefit analysis (e.g., Brent 1996; Campbell and Brown 2003). However, at a closer look, the methodology can hardly be presented as thé methodology to address thé equity concerns of a transport investment project.

The methodology of distributional weights has been developed to address policy concerns regarding the distribution of welfare over members of the present generation (although, more recently, it also has been applied to the distribution between generations; e.g., Nordhaus 2007; Stern 2008). Given an existing distribution of income, decisionmakers may attach a different value (weight) to the creation of a certain monetary gain for different groups (Schofield 1987). The theoretical underpinning of distributional weights lies, at least in part, in the observation that gains or losses in monetary terms do not necessarily represent the actual gains or losses in terms of utility. It may be expected that some form of diminishing marginal utility of income will apply: the higher the income, the lower the marginal utility of a certain monetary gain (Mishan 1976; Johansson-Stenman 2005). Following this observation, it is then argued that different weights should be ascribed to the net benefits reaped by different income groups. The net benefits received by low-income groups should receive a 'higher' weight, the net benefits obtained by highincome groups a 'lower' weight. In addition, decision-makers could deliberately attach a higher weight to the net benefits reaped by a particular population group, based on a political preference for projects that are beneficial for that group. In either way, the application of distributional weights may subsequently change the ranking of project alternatives, with alternatives generating benefits for lower income groups or other groups of concern performing relatively better in comparison to an un-weighted cost-benefit analysis.

Based on this brief description of the methodology, a first limitation of the application of distributional weights may be clear: the methodology is only relevant if decision-makers consider equalization as their guiding distributive principle and want to reduce existing income gaps. The application of distributional weights cannot help decision-makers if they prefer transport projects with an equal distribution of net benefits, or in case they seek to 
avoid selecting transport projects with a disproportionate distribution of net benefits to particular income groups.

Second, while distributional weights may help in improving the 'score' of transport projects that reduce existing income gaps, there is no guarantee that projects that have this effect will always score better than other projects (see also Mishan 1976, pp. 23-24). For instance, a project alternative that generates substantially more net benefits than any other alternative may still rank best, even if a weighting procedure is applied, despite the fact that the majority of net benefits of that alternative is reaped by high-income groups. Thus, the application of distributional weights cannot even support decision-makers who are concerned about income gaps in society and seek to select transport projects that to some extent equalize these income differences. This is so because the employment of distributional weights only changes the scores of different project alternatives, but does not provide decision-makers with actual information on the distributive impacts of each alternative. As a result, decision-makers cannot identify and subsequently select the alternative with the desired, fair, distribution of net benefits. Furthermore, it also does not provide policy makers with information that enables them to develop project alternatives that perform well in light of the equity concerns under consideration. The same analysis largely holds true for equity values.

The focus on the substance of the equity analysis in the CBA context thus stresses, in line with the literature but in a more systematic way, the limitations of the dominant 'equity' methodologies. First, both distributional weights and equity values are limited in terms of the types of distributive concerns that can be addressed. Neither methodology can address the distribution of all (sets of) benefits/costs distinguished in this paper. Second, neither methodology is suitable to address all possible policy concerns about the way a given benefit or cost is distributed over groups in society. Distributional weights are only relevant for decision-makers concerned about equalization, not for those concerned about equality or the avoidance of disproportionate distributions. Third, neither the application of distributional weights nor equity values opens up the 'black-box' of cost-benefit analysis: neither method actually generates data on the distributive impacts of project alternatives. As a consequence, the methodologies cannot assist decision-makers concerned about equity issues in developing transport projects with the desired outcomes, nor in selecting transport projects that generate a fair, and hence desired, distribution of benefits.

Given the variety in possible equity concerns, alternative methodologies will have to be developed if decision-makers want to address equity concerns within the CBA context. As argued in this paper, the development of such methodologies should start from the substance of the equity analysis, i.e. with the question: What are our distributive concerns? Only based on an explicit reflection on, and answer to, this question is it possible to develop adequate methodologies that can address the equity concerns on the agenda of decision-makers and/or the wider public. In line with much, but not all, of the literature, it is highly likely that this search for new methodologies will result in a separate equity analysis and separate equity indicators, in addition to the standard CBA indicators (net present value, benefit-cost ratio, and internal rate of return) (e.g., Beatley 1988; Needham 2006), despite the possible drawbacks of such an approach (Sayers et al. 2003). The shape and form of this equity analysis will differ, depending on the equity concern of decisionmakers and/or the wider public. For instance, if decision-makers are concerned about equalizing mobility-enhancing benefits, then a cost-effectiveness analysis could well be carried out, in addition to the cost-benefit analysis, in order to determine which project alternative contributes most to the goal of equalization. When such a separate equity analysis is linked closely to the CBA context-e.g., in terms of data needs and types of 
indicators to be developed-it may become accepted in everyday practice (see Martens 2007 for an application to mobility-enhancing benefits; see also Geurs et al. 2009). The importance of such a separate equity analysis lies not only in fact that it will assist decision-makers in selecting projects alternatives that generate a fair distribution of benefits or costs. Perhaps just as important is the fact that an explicit assessment of the equity implications of transport projects may encourage policy makers to develop project alternatives that perform well in terms of the equity concerns under consideration.

\section{Conclusion and discussion}

While distributive aspects have been a topic of discussion in relation to cost-benefit analysis, little systematic thought has been given to the substance of such an equity analysis in evaluating transport projects. The goal of this paper was to explore the various directions such an equity analysis could take. This exploration has resulted in the identification of three different types of equity concerns in which decision-makers-and the wider public - might be interested. The expectation is that the overview of possible equity concerns provided in the paper will create a more solid base for a discussion about the distributive question in the CBA context. It may help to direct the discussion away from methodological issues towards actual distributive concerns. The latter issue should be leading - method should follow substance. Thus, once decision-makers agree which equity concern is important enough to be addressed within the CBA context, a more fruitful discussion is possible about how these concerns could be dealt with in a methodological sense.

The decision regarding the focus of the equity analysis and the distributive principle to use as a yardstick is ultimately a political one, based on the equity concerns that dominate in a particular place and time. However, an argument could be developed that suggests that mobility-enhancing benefits should be at the heart of the equity analysis. The argument consists of two components, one discarding other equity concerns, one in favor of mobilityenhancing benefits.

First, there are good reasons to discard net benefits as the focus of the equity analysis. While it is reasonable to translate costs and benefits into monetary terms at an aggregate level, it is much less reasonable to do so at an individual or group level. For instance, while a low income group may reap net benefits from a transport projects due to a reduction in road accidents, they may actually experience an increase in out-of-pocket costs due to increased vehicle operation costs. Likewise, population groups vulnerable to air pollution, like the elderly, may receive net benefits from a transport project as a result of substantial travel time savings, but may actually experience an increase in air pollution level from the same to project. This suggests that a mere focus on the distribution of net benefits seems unsatisfactory from a perspective of distributive justice, as it does not address the underlying equity concerns.

Second, it can be argued that existing institutional arrangements greatly reduce the necessity to focus the equity analysis on all benefits and costs generated by a transport project. This holds especially for the environmental costs produced by new transport investments, as most Western countries have explicit norms regarding e.g. the maximum concentration of air pollutants or noise levels in residential areas. These norms can be regarded as an implicit version of the distributive principle 'avoidance of disproportionate distributions', as these norms de facto determine which level of distribution is still acceptable and which level is unacceptable. For example, consider a transport project that generates a given level of total air pollution. This project will not receive statutory approval 
based on environmental norms, if the total pollution generated by the project is distributed in such a way that the air pollution in even just one neighborhood passes the legal threshold level. In contrast, the same project would not be rejected on environmental grounds, if the same total level of pollution would be distributed in such a way that the level of air pollution in no neighborhood exceeds the threshold level. Hence, it can be argued that environmental norms are a tool of distributive justice: the norms, if upheld adequately, guarantee that no citizen will receive a disproportionately high level of air or noise pollution, irrespective of location of residence, race, or income level. Since in most Western countries norms are in force for the majority of environmental externalities generated by transport projects (e.g., noise, particles, $\mathrm{NO}_{x}$ ), it can be argued that there is no need to explicitly address the distribution of these environmental externalities within the CBA context.

The arguments suggesting that the equity analysis of transport projects should focus on mobility-enhancing benefits have already been mentioned above. Transport projects are a government's key tool to provide citizens with mobility-enhancing benefits and the only tool to provide them with reductions in travel time. Furthermore, citizens have few possibilities to improve their potential mobility, certainly if they have exhausted private possibilities of vehicle purchase (car, motorcycle, bicycle, etc) or if they cannot afford to purchase or maintain these vehicles. The way new transport infrastructures distribute especially travel time savings over citizens thus becomes of the utmost importance for citizen's future mobility. Furthermore, given the increasing importance of mobility and accessibility in contemporary highly mobile societies, the level of potential mobility is becoming of the utmost importance for citizen's opportunities (e.g., Kaufmann et al. 2004). A failure to explicitly account for the way in which transport projects distribute mobilityenhancing benefits over various population groups, may generate groups of citizens that have low levels of potential mobility and, hence, lack the opportunities to take advantage of high quality education and health services, to access job markets and thus advance economically, to keep in contact with friends, or to enjoy recreational facilities. The growing body of literature on transport and social exclusion suggests that this process has been taking place over the past decades, resulting in reduced potential mobility for marginalized groups in society (e.g., Cass et al. 2005; Cebollada 2008; Hine and Mitchell 2001). Taken together, these arguments suggests that the equity analysis carried out within the CBA context should focus first and foremost on the way in which mobility-enhancing benefits are distributed over population groups.

Acknowledgments The paper is one of the results of a larger research project on transport and justice funded by the Volvo Research and Educational Foundations. Part of the ideas presented in the paper have been developed within the framework of an inquiry into the equity aspects of cost-benefit analysis on behalf of the Israeli Ministry of Transport. The author would like to thank the anonymous reviewers, who have helped in substantially improving the argument made in the paper.

Open Access This article is distributed under the terms of the Creative Commons Attribution Noncommercial License which permits any noncommercial use, distribution, and reproduction in any medium, provided the original author(s) and source are credited.

\section{References}

Adler, M.D., Posner, E.A. (eds.): Cost-Benefit Analysis: Legal, Economic and Philosophical Perspectives. The University of Chicago Press, Chicago (2001)

Bae, C.-H.C., Sandlin, G., Bassok, A., Kim, S.: The exposure of disadvantaged populations in freeway airpollution sheds: a case study of the Seattle and Portland regions. Environ. Plan. B: Plan. Des. 34(1), 154-170 (2007) 
Beatley, T.: Equity and distributional issues in infrastructure planning: a theoretical perspective. In: Stein, J.M. (ed.) Public Infrastructure Planning and Management, pp. 208-226. Sage, Newbury Park (1988)

Benenson, I., Martens, K., Rofé, Y., Kwartler, A.: Public transport versus private car: GIS-based estimation of accessibility applied to the Tel Aviv metropolitan area. The Ann. Reg. Sci. 1-17 (2010)

Blumenberg, E.A.: Engendering effective planning: spatial mismatch, low-income women, and transportation policy. J. Am. Plan. Assoc. 70(3), 269-281 (2004)

Boucher, D., Kelly, P. (eds.): Social Justice: From Hume to Walzer. Routledge, London (1998)

Brainard, J.S., Jones, A.P., Bateman, I.J., Lovett, A.A., Fallon, P.J.: Modelling environmental equity: access to air quality in Birmingham, England. Environ. Plan. A 34(4), 695-716 (2002)

Brent, R.J.: Applied Cost-Benefit Analysis. Edward Elgar Publishing, Cheltenham (1996)

Bristow, A.L., Nellthorp, J.: Transport project appraisal in the European Union. Transp. Policy 7(1), 51-60 (2000)

Cain, A., Jones, P.: Does urban road pricing cause hardship to low-income car drivers? An affordability based approach. In: 87th Annual Meeting of the Transportation Research Board, Washington, DC (2007)

Campbell, H.F., Brown, R.P.C.: Benefit-Cost Analysis: Financial and Economic Appraisal Using Spreadsheets. Cambridge University Press, Cambridge (2003)

Cass, N., Shove, E., Urry, J.: Social Exclusion, Mobility and Access. Sociol. Rev. 53(3), 539-555 (2005)

Cebollada, À.: Mobility and Labour Market Exclusion in the Barcelona Metropolitan Region. J. Transp. Geogr. 17(3), 226-233 (2008)

Dong, X., Ben-Akiva, M.E., Bowman, J.L., Walker, J.L.: Moving from Trip-Based to Activity-Based Measures of Accessibility. Transp. Res. Part A: Policy Pract. 40(2), 163-180 (2006)

Fischer, T.B.: Strategic Environmental Assessment in Transport and Land Use Planning. Earthscan, London (2002)

Forkenbrock, D.J., Schweitzer, L.A.: Environmental justice in transportation planning. J. Am. Plan. Assoc. 65(1), 96-111 (1999)

Frank, R.H.: Why is cost-benefit analysis so controversial? In: Adler, M.D., Posner, E.A. (eds.) CostBenefit Analysis: Legal, Economic and Philosophical Perspectives, pp. 77-94. The University of Chicago Press, Chicago (2001)

Geurs, K.T., Boon, W., Van Wee, B.: Social impacts of transport: literature review and the state of the practice of transport appraisal in the Netherlands and the United Kingdom. Transp. Rev. 29(1), 69-90 (2009)

Geurs, K.T., van Wee, B.: Accessibility evaluation of land-use and transport strategies: review and research directions. J. Transp. Geogr. 12(2), 127-140 (2004)

Gunn, H.F.: An introduction to the valuation of travel-time savings and losses. In: Hensher, D.A., Button, K.J. (eds.) Handbook of Transport Modelling, pp. 433-448. Elsevier, Amsterdam (2000)

Handy, S.L., Niemeier, D.A.: Measuring accessibility: an exploration of issues and alternatives. Environ. Plan. A 29(7), 1175-1194 (1997)

Hill, M.: Planning for Multiple Objectives: An Approach to the Evaluation of Transportation Plans. Regional Science Research Institute, Philadelphia, PA (1973)

Hine, J.P., Mitchell, F.: Better for everyone? Travel experiences and transport exclusion. Urban Stud. 38(2), 319 (2001)

Holland, A.: The assumptions of cost-benefit analysis: a philosopher's view. Available via http://www. lancs.ac.uk/users/philosophy/awaymave/onlineresources/assumption \%20of\%20cost-benefit\%20analysis\% 20_a\%20holland_.pdf. Accessed 31 May 2006, TWP 96-09 (1996)

Ihlanfeldt, K.: Intra-urban job accessibility and Hispanic youth employment rates. J. Urban Econ. 33(2), 254-271 (1993)

Jara-Diaz, S.R.: Allocation and valuation of travel time savings. In: Hensher, D.A., Button, K.J. (eds.) Handbook of Transport Modelling. Pergamon, Oxford (2000)

Johansson-Stenman, O.: Distributional weights in cost-benefit analysis: Should we forget about them? Land Econ. 81(3), 337-352 (2005)

Kaufmann, V., Bergman, M.M., Joye, D.: Motility: mobility as capital. Int. J. Urban Reg. Plan. 28(4), 745-756 (2004)

Kelman, S.: Cost-benefit analysis: an ethical critique. In: Donaldson, T., Werhane, P.H., Cording, M. (eds.) Ethical Issues in Business: A Philosophical Approach, pp. 559-564. Prentice Hall, Upper Saddle River, NJ (2002)

Kolm, S.-C.: Modern Theories of Justice. MIT Press, Cambridge, MA (1996)

Kwan, M.-P.: Gender and individual access to urban opportunities: a study using space-time measures. Prof. Geogr. 51(2), 210-227 (1999) 
Kwok, R.C.W., Yeh, A.G.O.: The use of modal accessibility gap as an indicator for sustainable transport development. Environ. Plan. 36(5), 921-936 (2004)

Levinson, D.: Identifying winners and losers in transportation. Transp. Res. Rec. J. Transp. Res. Board 1812, 179-185 (2002)

Lichfield, N.: Cost benefit analysis in town planning: case study Swanley. Urban Stud. 3(3), 215-249 (1966)

Lucas, K.: Running on Empty: Transport, Social Exclusion and Environmental Justice. Policy Press, Bristol (2004)

Mackie, P.J., Jara-Diaz, S., Fowkes, A.S.: The value of travel time savings in evaluation. Logist. Transport. Rev. 37(2-3), 91-106 (2001)

Martens, K.: Basing transport planning on principles of social justice. Berkeley Plan. J. 19, 1-17 (2006)

Martens, K.: Integrating Equity Considerations into the Israeli Cost-Benefit Analysis: Guidelines for Practice. Israeli Ministry of Transport, Tel Aviv. Available via http://radboud.academia.edu/KMartens/Papers/ 952496/Martens_K._1997_Integrating_Equity_Considerations_into_the_Israeli_Cost-Benefit_Analysis_ Guidelines_for_Practice._Israeli_Ministry_of_Transport_Tel_Aviv (2007)

Miller, D.: Principles of Social Justice. Harvard University Press, Cambridge (1999)

Mills, G.S., Neuhauser, K.S.: Quantitative methods for environmental justice assessment of transportation. Risk Anal. 20(3), 377-384 (2000)

Mishan, E.J.: Elements of Cost-Benefit Analysis. George Allen and Unwin, London (1976)

Morello-Frosch, R., Pastor, M., Sadd, J.: Environmental justice and Southern California's "riskscape": the distribution of air toxics exposures and health risks among diverse communities. Urban Aff. Rev. 36(4), 551-578 (2001)

Needham, B.: Planning, Law and Economics: The Rules We Make for Using Land. Routledge, London (2006)

Nordhaus, W.D.: Review: a review of the "stern review on the economics of climate change". J. Econ. Lit. 45(3), 686-702 (2007)

Nozick, R.: Anarchy, State, and Utopia. Basic Books, New York (1974)

Pucher, J., Dijkstra, L.: Making walking and cycling safer: lessons from Europe. Transp. Q. 54(3), 25-50 (2000)

Rietveld, P., Rouwendaal, J., van der Vlist, A.: Equity issues in the evaluation of transport policies and transport infrastructure projects. In: van Geenhuizen, M., Reggiani, A., Rietveld, P. (eds.) Policy Analysis of Transport Networks, pp. 19-36. Aldershot, Ashgate (2007)

Sadurski, W.: Giving Desert Its Due: Social Justice and Legal Theory. D. Reidel Publishing Company, Dordrecht (1985)

Sager, T.: Footloose and forecast-free: hypermobility and the planning of society. Eur. J. Spat. Dev. 2005(17), 1-23 (2005)

Sayers, T.M., Jessop, A.T., Hills, P.J.: Multi-criteria evaluation of transport options-flexible, transparent and user-friendly? Transp. Policy 10(2), 95-105 (2003)

Schade, W., Mackie, P.J., Nellthorp, J., Burgess, A., Renes, G.: Methodological advances in project assessment within a european context. Report within the Framework of the FP5 IASON Project (Integrated Appraisal of Spatial Economic and Network Effects of Transport Investments and Policies) (2004)

Schofield, J.A.: Cost-Benefit Analysis in Urban and Regional Planning. Allen \& Unwin, London (1987)

Schweitzer, L., Stephenson, M.: Right answers, wrong questions: environmental justice as urban research. Urban Stud. 44(2), 319-337 (2007)

Schweitzer, L., Valenzuela, A.: Environmental injustice and transportation: the claims and the evidence. J. Plan. Lit. 18(4), 383-398 (2004)

Sen, A.K.: The discipline of cost-benefit analysis. In: Adler, M.D., Posner, E.A. (eds.) Cost-Benefit Analysis: Legal, Economic and Philosophical Perspectives, pp. 95-116. The University of Chicago Press, Chicago (2001)

Smith, D.M.: Geography and Social Justice. Blackwell, Cambridge (1994)

Stern, N.: The economics of climate change. Am. Econ. Rev. 98(2), 1-37 (2008)

Stoll, M.A.: Geographical skills mismatch, job search and race. Urban Stud. 42(4), 695-717 (2005)

Walzer, M.: Spheres of Justice: A Defense of Pluralism and Equality. Basic Books, New York (1983)

Williams, R.W.: The contested terrain of environmental justice research: community as unit of analysis. Soc. Sci. J. 36(2), 313-328 (1999)

Young, I.M.: Justice and the Politics of Difference. Princeton University Press, Princeton, NJ (1990)

\section{Author Biography}

Karel Martens is an assistant professor at the Institute for Management Research, Radboud University Nijmegen, the Netherlands. His main research interests include transport and justice, the land use-transport 
interrelationship, parking and interconnectivity of transport modes. He has published and presented a number of papers on transport and justice, among others in Transportmetrica (2011, with co-author), The Annals of Regional Science (2010, with co-authors), Transportation Research Records (2010, with coauthors), Berkeley Planning Journal (2006), and at the Annual Conference of the Transportation Research Board (2007, 2009, 2011). 